Objectives: To investigate the correlation of serum COMP levels with the articular cartilage damage based on sonographic knee cartilage thickness (KCT) and disease characteristics in RA.

Methods: A total of 61 RA patients and 27 healthy controls were recruited in this study. Serum samples were obtained from all subjects to determine the COMP levels. All subjects had bilateral ultrasound scan of their knees performed by a single radiologist; who was blinded to the details of the subjects. The KCT was based on the mean of measurements at 3 sites; the medial condyle, lateral condyle and intercondylar notch (Figure 1). Besides, the RA patients were assessed for their disease activity based on DAS 28.

Results: Serum COMP concentrations were significantly elevated in the RA patients compared to the controls $(p=0.001)$. The serum COMP levels had an inverse relationship with bilateral KCT in RA subjects and the healthy controls. However, the association was statistically insignificant for bilateral knees in the control arm. COMP correlated significantly with disease activity based on DAS $28(r=0.299, p=0.010)$, disease duration $(r=0.439, p=<0.05)$ and mean left KCT $(r=-0.285, p=0.014)$ in RA (Table 1). Erythrocyte sedimentation rate (ESR) and C-reactive protein (CRP) which are the traditional markers of inflammation; demonstrated a significant positive correlation with the DAS 28 scores $(r=0.372$, $p=0.003$ for ESR; $r=0.305, p=0.017$ for CRP) comparable to the serum COMP. However, neither ESR nor CRP had a significant association with the KCT, as opposed to the serum COMP.

Table 1. Correlation of Serum COMP levels with Clinical Parameters in RA

\begin{tabular}{lcc}
\hline Parameter & $r$ & $p$ value \\
\hline Age & 0.214 & 0.094 \\
BMI & 0.122 & 0.259 \\
DAS 28 & 0.299 & 0.010 \\
ESR & 0.065 & 0.311 \\
CRP & 0.027 & 0.418 \\
Disease duration & 0.439 & $<0.05$ \\
Mean Right KCT & -0.177 & 0.088 \\
Mean Left KCT & -0.285 & 0.014
\end{tabular}

KCT: knee cartilage thickness.

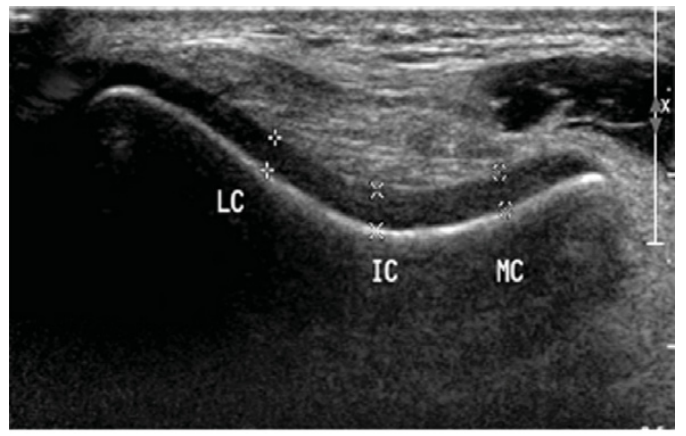

LC Lateral Condyle, MC: Medial Condyle, $N$. Intercondylar notch

Figure 1 : Sites of sonographic knee cartilage thickness measurement

Conclusions: The serum COMP is a promising biomarker in RA which reflects disease activity and damage to the articular cartilage. Serum COMP appeared superior to the traditional markers in RA i.e ESR and CRP in predicting sonographic KCT.

References:

[1] Andersson ML, Svensson B, Petersson IF, et al. Early increase in serumCOMP is associated with joint damage progression over the first five years in patients with rheumatoid arthritis. BMC Musculoskelet Disord. 2013;14:229.

[2] Happonen KE, Saxne T, Aspberg A, et al. Regulation of complement by cartilage oligomeric matrix protein allows for a novel molecular diagnostic principle in rheumatoid arthritis. Arthritis Rheum. 2010;62:3574-83.

[3] Happonen KE, Saxne T, Geborek P, et al. Serum COMP-C3b complexes in rheumatic diseases and relation to anti-TNF-alpha treatment. Arthritis Res Ther. 2012;14:R15.

Disclosure of Interest: None declared

DOI: 10.1136/annrheumdis-2017-eular.1213

\section{AB0276 EVALUATION OF ADHERENCE TO DRUG TREATMENT IN PATIENTS WITH RHEUMATOID ARTHRITIS}

A.E.-A.M. Alhefny ${ }^{1}$, S.A. Mobasher ${ }^{2}$, M.A. Abd El-Rahman ${ }^{1}$, N.H. Shedid ${ }^{1}$ H.M. Sakr ${ }^{3}$, R.M. Hassan ${ }^{1} .{ }^{1}$ Ain Shams University Hospitals, Cairo, Egypt; ${ }^{2}$ Internal Medicine and Rheumatology; ${ }^{3}$ Radiology, Ain Shams University Hospitals, Cairo, Egypt

Background: the medication adherence is very vital issue nowadays, especially in RA patients.

Objectives: to measure the frequency of the adherence in RA patients, and evaluate the common factors influencing RA patients adherence to drug treatment aiming at improving disease outcome.

Methods: a Prospective cohort study of 100 patients with RA under treat- ment, fulfilled the American College of Rheumatology/European League Against Rheumatism (ACR/ EULAR) (1) criteria. All patients subjected to Full history taking and clinical examination, (DAS 28 ESR), Health Assesment Questionnaire (HAQ) score, Visual Analouge Scalez (VAS) scale, CBC, ESR, CRP titer, RF titer, ACPA titer and Power Doppler U/S for both hands, patients also respond to specific questionnair containing questions about sociodemographic data, medication, health care system and Compliance Questionnaire of Rheumaology (CQR).

Results: The baseline adherence rate $(C Q R \geq 80)$ was $37 \%$. The nonadherent $R A$ patients to drug treatment were older, living outside Cairo, with low educational level and smokers, they also had higher DAS28ESR score, HAQscore, ESR, CRP titer and more frequent active synovitis in Doppler ultrasound. The cost of medication $(61 \%)$, non-availability of medication in pharmacy $(58 \%)$, forgetting the medication $(36 \%)$, patients' lack of belief in the benefit of treatment $(38 \%)$, inadequate follow up or discharge planning (23\%) and polypharmacy (medication load) $(20 \%)$ were the most common factors in nonadherent patients table (3). After 9 months of the follow up and trying to correct the causes of nonadherence, the adherence rate increased to $(68.75 \%)$. Also there was improvement in disease activity, improvement in functional state and improvement in the quality of life.

Conclusions: Low adherence rate was associated with higher disease activity, functional disability. Patient education, financial support, good physician patient relationship, simplification of the prescription, facilitation their communication, using MSUS were found to improve the patient adherence and improve the disease outcome.

\section{References:}

[1] Aletaha D, Neogi T, Silman A et al, Rheumatoid arthritis classification criteria: an American College of Rheumatology/European League against Rheumatism collaborative initiative. Arthritis Rheum 2010:62:2569-2581.

[2] Dowman B, Campbell R, Zgaga $L$ et al, Estimating the burden of rheumatoid arthritis in Africa: A systematic analysis. J Global Health 2012;2(2):1-9.

[3] Wasserman A, Diagnosis and Management of Rheumatoid Arthritis.American Family Physician J 2011:84(11):1245-1252.

Disclosure of Interest: None declared

DOI: 10.1136/annrheumdis-2017-eular.5785

\section{AB0277 PATIENT REPORTED OUTCOMES EXPLAIN THE LACK OF AGREEMENT BETWEEN PHYSICIAN AND PATIENT PERCEIVED REMISSION IN EARLY RHEUMATOID ARTHRITIS}

S.A. Turk ${ }^{1}$, L. Rasch ${ }^{2}$, W.F. Lems ${ }^{1,2}$, L. van Tuyl ${ }^{2}$, D. van Schaardenburg ${ }^{1,3}$, M.M. ter Wee ${ }^{2} .{ }^{1}$ Amsterdam Rheumatology and Immunology Center/ Reade; ${ }^{2}$ Amsterdam Rheumatology and Immunology Center/ VU University Medical Center; ${ }^{3}$ Amsterdam Rheumatology and Immunology Center/Academical Medical Center, Amsterdam, Netherlands

Background: Rheumatoid arthritis (RA) patients increasingly reach a state of absence of disease activity, or remission. However, the proportion of patients classified as in remission varies substantially between definitions and are often determined by disease activity score (DAS). But, the importance of patients' perspective is increasingly recognized, which often result in discordance between patients and physician assessment.

Objectives: To determine how often patients and physicians agree on a state of remission according to different definitions, as well as the difference in patient reported and clinical outcomes between patients in and not in self-perceived remission.

Methods: In 84 consecutive early RA patients, Boolean remission, EULAR

Table 1

\begin{tabular}{|c|c|c|c|c|c|c|}
\hline \multirow[t]{2}{*}{ Physician } & \multicolumn{3}{|c|}{$\begin{array}{l}\text { Remission according } \\
\text { to physician }\end{array}$} & & & \\
\hline & PhR & NPhR & $\mathrm{T}$ & & & \\
\hline PatR & $41(61)$ & $4(23)$ & $45(54)$ & & & \\
\hline NPatR & $26(39)$ & $13(77)$ & $39(46)$ & & & \\
\hline $\mathrm{T}$ & $67(80)$ & $17(20)$ & 84 & & & \\
\hline \multirow[t]{2}{*}{ Boolean } & \multicolumn{3}{|c|}{ Remission } & \multicolumn{3}{|c|}{ No remission } \\
\hline & PhR & NPhR & $\mathrm{T}$ & $\mathrm{PhR}$ & NPhR & $T$ \\
\hline PatR & $20(87)$ & $0(0)$ & $20(87)$ & $21(48)$ & $4(24)$ & $25(41)$ \\
\hline NPatR & $3(13)$ & $0(0)$ & $3(13)$ & $23(52)$ & $13(77)$ & $36(59)$ \\
\hline $\mathrm{T}$ & $23(100)$ & $0(0)$ & 23 & $44(72)$ & $17(28)$ & 61 \\
\hline
\end{tabular}

\begin{tabular}{|c|c|c|}
\hline EULAR response & Good & Moderate \\
\hline
\end{tabular}

\begin{tabular}{llllllllll}
\hline PatR & $39(65)$ & $3(60)$ & $42(65)$ & $1(20)$ & $1(14)$ & $2(17)$ & $1(50)$ & $0(0)$ & $1(14)$
\end{tabular}

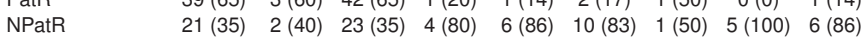

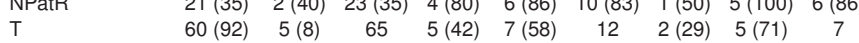

\begin{tabular}{llll}
\hline ACR & ACR 70 & ACR $50($ not 70$)$ & non (not 50)
\end{tabular}

\begin{tabular}{|c|c|c|c|c|c|c|}
\hline N & & HU & & & 1504 & \\
\hline & $\mathrm{PhR}$ & NPhR & $\mathrm{T}$ & $\mathrm{PhR}$ & NPhF & \\
\hline
\end{tabular}

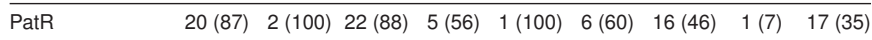

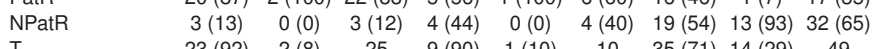

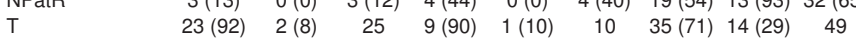

Values are expressed as number (\%). PhR = physician perceived remission, NPhR = no physician perceived remission, PatR $=$ patient perceived remission, NPatR $=$ no patient perceived remission, $\mathrm{T}=$ total. 
response and ACR 70 criteria were determined after 12 weeks of treatment with a fixed schedule methotrexate and prednisone. Physician perceived remission (PhR) was defined as a global assessment of $\leq 20$ on a visual analogue scale, phrased: "How active do you think the RA of your patient is today?". Patient perceived remission (PatR) was phrased as: "Would you say that, at this moment, your disease activity is as good as gone? Yes/no". In patients in PhR, the change in components of the DAS44 and questions of the Rheumatoid Arthritis Impact of Disease (RAID) and Health Assessment Questionnaire (HAQ) were compared between patients in and not in self-perceived remission.

Results: The agreement on remission between patients and physicians was $64 \%$ and was dependent of the definition of remission. In Boolean remission, EULAR good response and ACR70 remission agreement was: $86 \%, 63 \%$ and $80 \%$ respectively (table). Patients in PhR, the patients in PatR had more improvement on all RAID subdomains. There were no significant differences in clinical outcomes (ESR was significantly different at baseline, but not after 12 weeks; see figure).

Figure. Comparison in improvement in patient reported and clinical outcomes after 12 weeks ol treatment, in patients in physician remission, who are and are not in self-perceived remission.

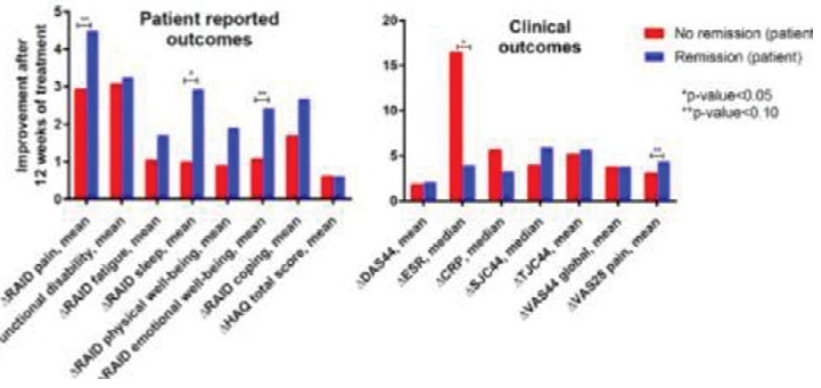

Conclusions: Two-third of the patients agreed with the physician on being in remission. In all different definitions for remission, this discordance between physician and patient on perceived remission remained similar. Patients in selfperceived remission had more improvement in components of the RAID, but not in clinical outcomes. Further research is needed to identify domains of patients perceived remission.

Disclosure of Interest: None declared

DOI: 10.1136/annrheumdis-2017-eular.3406

\section{AB0278 ULTRASOUND EXAMINATION IN DIAGNOSIS OF EARLY RHEUMATOID ARTHRITIS}

W. Hamdi ${ }^{1}$, S. Miladi ${ }^{1}$, K. Matallah ${ }^{1}$, M. Bouaziz ${ }^{2}$, D. Kaffel ${ }^{1}$, I. Zouch ${ }^{1}$, M.M. Kchir ${ }^{1}$. ${ }^{1}$ Rheumatology department; ${ }^{2}$ Radiology department, Institute Kassab of Orthopedics, Manouba. Tunisia, Tunis, Tunisia

Background: Fortunately, management of RA at the early stage has become possible thanks to both the emergence of new biotherapies and the strategy treat to target. Musculoskeletal ultrasound (US) is a potent tool for the detection of synovitis, effusion and bone erosion in RA.

Objectives: The aim of this study was to assess the contribution of US in diagnosing RA at the early stage of the disease.

Methods: A cross-sectional study was performed during 2 years. Patients with a history of inflammatory joint pain for $\geq 6$ weeks and $\leq 2$ years with synovitis of at least one joint were enrolled in this study. All patients underwent clinical assessement, laboratory tests and plain radiography of hands and feet.US was assessed within one week of clinical examination. Synovitis and erosion were defined according to the OMERACT.

Results: One hundred patients were included in this study with an average age of $51,8 \pm 14,6$ years-old. Female outnumbered male with a sex ratio of 3,8 . The mean duration of the disease was $10,9 \pm 7,4$ months. When admitted to our department and after clinical examination it was found that $31 \%$ of patients presented polyarthritis, $4 \%$ had oligoarthritis and $7 \%$ suffered from monoarthritis. US findings: US was found to be more sensitive than clinical examination to detect synovitis. Among the 2200 joints assessed by US, a synovitis was detected in $81 \%$ patients, an intra-articular effusion in $36 \%$ patients and PD signals in $51 \%$ patients. Also, flexor tenosynovitis were present in $55 \%$ patients and extensor tenosynovitis in $59 \%$ patients. Erosions were more detected in plain radiography $(70 \%)$ than in US $(41 \%)$. Clinical parameters (VAS, duration of morning stiffness, number of night awakens, TJC) were not correlated with most US findings. Nevertheless, correlation was detected for US effusion $(r=0,250, p=0,028)$ and for US Doppler $(r=0,289, p=0,011)$ with SJC. PDUS examination correlated with CRP results $(r=0,302, p=0,023)$ but not with ESR results. A significant, positive correlation was observed between erosions in X-rays or US assessment $(r=0,342$, $p=0,002)$. The US detected synovitis in $25 \%$ of patients who had no swollen joint at the clinical examination when admitted to our department and had detected erosions in $9 \%$ of patients having negative plain $X$ rays.

Conclusions: Ultrasound appears as a sensitive tool to detect subclinical synovitis (25\%) and infra- radiological erosions (9\%). It helps us to make an early diagnosis and start appropriate treatment before the onset of irreversible joint destruction.
Disclosure of Interest: None declared

DOI: 10.1136/annrheumdis-2017-eular.6230

\section{AB0279 HIGH RATE OF DISABILITY PENSION IN CHILEAN RHEUMATOID ARTHRITIS PATIENTS WITHOUT ACCESS TO BIOLOGICS. HOSPITAL PADRE HURTADO EXPERIENCE}

S.E. Ibáñez Vodnizza, O. Valenzuela, F. Silva, M.J. Villar. Rheumatology department, Clínica Alemana de Santiago/Hospital Padre Hurtado, Santiago, Chile

Background: Until the year 2016, most of the Chilean rheumatoid arthritis patients in the public health system did not have acces to biologic treatment. Now the access is limited to those with high disease activity (DAS $28>5.1$ ).

Objectives: Our main objective was to evaluate the rate of patients benefited by disability pension within the group of rheumatoid arthritis patients seen in our center, before the introduction of biologic treatment for those with high disease activity. Our secondary objective was to estimate the association between having a disability pension and the characteristics of the patients.

Methods: Consecutive rheumatoid arthritis patients (according to the ACR 2010 criteria), 18 years old or older, that attended to our rheumatology consult between September and December of 2015, were included. Patients with other types of pensions (retirement) were excluded. Information about work status, gender, age, years since diagnosis, medications used, DAS 28 ESR and its variables was collected.

Results: 104 patients were included. $38.5 \%$ had a disability pension. We found significant differences between the patients with and without disability pensions for age, years since diagnosis, tramadol use, the number of tender joints, the number of swollen joints and DAS 28 ESR (Table 1). After multivariate logistic regression, age (OR $1,95 \% \mathrm{Cl} 1.02-1.15)$, tramadol use (OR $0.3,95 \% \mathrm{Cl}$ $0.08-0.92$ ) and the number of swollen joints (OR 1.4, 95\% Cl 1-1.96) continued to be significantly associated.

Table 1. Disease characteristics

\begin{tabular}{lcccc}
\hline & All & $\begin{array}{c}\text { Without Disability } \\
\text { Pension }\end{array}$ & $\begin{array}{c}\text { With Disability } \\
\text { Pension }\end{array}$ & P \\
\hline Number of patients (\%) & $104(100)$ & $64(61.5)$ & $40(38.5)$ & NA \\
Female (\%) & $86(82.7)$ & $53(82.8)$ & $33(82.5)$ & NS \\
Age (median, IQR) & $55.5(15)$ & $52.5(18)$ & $58(15)$ & 0.002 \\
Years since diagnosis (median, IQR) & $8.8(12.2)$ & $5.8(8.2)$ & $12.3(19.1)$ & $<0.001$ \\
Number of DMARDs used (median, IQR) & $2(2)$ & $1(2)$ & $2(2)$ & NS \\
Prednisone users (\%) & $89(85.6)$ & $52(81.3)$ & $37(92.5)$ & NS \\
NSAIDs users (\%) & $75(72.1)$ & $46(71.9)$ & $29(72.9)$ & NS \\
Acetaminophen users (\%) & $68(65.4)$ & $39(60.9)$ & $29(72.5)$ & NS \\
Tramadol users (\%) & $35(33.7)$ & $13(20.3)$ & $22(55)$ & 0.001 \\
Number of tender joints (median, IQR) & $4(6)$ & $3(5)$ & $6(11)$ & 0.018 \\
Number of swollen joints (median, IQR) & $2(4)$ & $1(4)$ & $3(8)$ & 0.012 \\
ESR (median, IQR) & $20.5(21)$ & $16.5(18)$ & $25(31)$ & NS \\
VAS pain (median, IQR) & $60(40)$ & $60(40)$ & $80(40)$ & NS \\
DAS 28 ESR (mean, SD) & $4.5(1.6)$ & $4.1(1.4)$ & $5(1.8)$ & 0.026 \\
\hline IQR
\end{tabular}

$\mathrm{IQR}=$ interquartile range, DMARDs $=$ Disease-Modifying Antirheumatic Drugs, NSAIDs = Nonsteroidal anti-inflammatory drugs, ESR $=$ Erythrocyte Sedimentation Rate, VAS $=$ Visual Analog Scale, DAS = Disease Activity Score, NS = Not significant.

Conclusions: Near forty percent of our rheumatoid arthritis patients, that did not have access to biologic treatment, were being paid a disability pension, and this condition was significatly associated with more years of age, tramadol use, and the number of swollen joints. The mean DAS 28 ESR in the patients with disability pension was 5 . The limit of a DAS $28>5.1$ to authorize the use of biologic treatment possibly will not help to reduce the rate of patients with disability pension in our group.

Disclosure of Interest: None declared

DOI: 10.1136/annrheumdis-2017-eular.2557

\section{AB0280 INFLUENCE OF HLA CLASS II ANTIGEN (DRB1 AND DQB1) ON THE PRODUCTION OF ANTI-CYCLIC CITRULLINATED PEPTIDE ANTIBODIES IN A TUNISIAN POPULATION}

S. Boussaid ${ }^{1}$, S. Kochbati ${ }^{2}$. ${ }^{1}$ Departement of Rheumatologie, la Rabta Hospital; ${ }^{2}$ Departement of Rheumatologie, Habib Thameur Hspital, tunis, Tunisia

Background: Rheumatoid arthritis (RA) is the most common chronic inflammatory rheumatism. It's a complex autoimmune disorder. The aim of this study is to focus on the relationship between HLA-DRB1 genes and RA specific antibodies against cyclic citrullinated peptides (anti-CCP antibodies).

Methods: This prospective study was performed on a total of 81 Tunisian patients with rheumatoid arthritis. All patients fulfilled the American College of Rheumatology (ACR 1987) criteria for RA. For each patient we assessed DNA and serum samples. The DNA was extracted from lymphocytes using a commercial kit (Quiagen). The HLA class II (DQB1 and DRB1) was performed by Polymerase Chain Reaction technique Specifying-sequence primers (PCR-SSP). The specific products of PCR were analyzed by $2.5 \%$ agarose gel electrophoresis. All tests include positive and negative controls appropriate for each blood sample. The phenotypes of patients were obtained through the Software One Lambda DNA/SOFTWARE (SSP2L-generic DRB/DQB). 